\title{
Putting Science into Farmer Practice: Validation of the Salt and Bottle Method to Determine Grain Moisture in Stored Maize
}

\author{
Ngatia Christopher Mugo \\ Postharvest Research Scientist; Kenya Agricultural Research Institute (KARI), Kabete, Nairobi, Kenya
}

Email address:

chrisngatia@yahoo.com, chrisngatia@gmail.com

To cite this article:

Ngatia Christopher Mugo. Putting Science into Farmer Practice: Validation of the Salt and Bottle Method to Determine Grain Moisture in Stored Maize. International Journal of Science, Technology and Society. Vol. 3, No. 2, 2015, pp. 51-54. doi: 10.11648/j.ijsts.20150302.13

\begin{abstract}
Maize storage among rural farmers is a common practice to conserve grain for future use and income generation. Storage is done in a variety of structures with the aim to maintain quality at an acceptable level. Farmers and other players in the grain trade know the negative influence of moisture and well dried grain stores better irrespective of the structure used. Introduction of metal silos for storage to reduce pest damage and the reliance on toxic chemicals for their control, did not address grain drying. Natural drying, a common practice among farmers has played vital role but with the new technology, a method that would determine when grain was adequately dry was needed. The Catholic Relief Services introduced the 'salt and bottle' method which works on the principle that dry salt does not stick on to a dry surface. The question was, at what moisture level would salt not stick to grain surface? The answer was provided through a laboratory assessment on maize samples collected from farmers in three dioceses, which indicated that between $12 \%$ and $16 \%$ grain moisture, negligible amounts of salt stuck on grain. At moisture above $12 \%$ maize cannot store safely for prolonged period in metal silos and drying in the shade or in the sun showed the extra time needed for successful metal silo storage.
\end{abstract}

Keywords: Maize Storage, Grain Moisture Content, Drying, Salt and Bottle, Validation

\section{Introduction}

The movement of harvested maize in Kenya can be tracked from farmers through the local marketing channels to larger storage systems, processors and finally the shelves of retail traders in urban centres. Along this chain, grain quality may change which can affect pricing and consumption. Moisture is one of the factors in grain quality and in order to ensure fairness in the maize trade, the Kenya Bureau of Standards (KeBS) has set quality standards in maize and other stored produce. The moisture content of stored maize grain should not exceed $13.5 \%$ according to the Kenya Standard Specification for dry shelled maize (Anon: 1977). Walker, (1994) noted that grain stored at higher moisture was likely to be damaged by insect pests and storage moulds with the associated risk of fungal toxins. If the objective in grain storage was to preserve the quality of food, deterioration caused by grain moisture has to be addressed. Produce drying at all levels is crucial. Grain drying is defined as the separation of excess or free water from the solid matter (Appert, 1987). The process ensures only grain with low moisture was stored, and should be regularly monitored throughout the storage period. In large storage systems, grain drying and its subsequent monitoring is satisfactory due to the level of investment on requisite equipment and training. The situation at farm level is rather wanting and this is where attention is required.

Hall (1970) observed that farmers have their own methods of telling if grain was dry enough to be stored. The traditional methods of determining grain moisture include biting, squeezing between thumb and fore finger nails, crushing, plunging the hand into the grain mass to "feel", smelling and dropping grain to hear the rattling sound on hitting a hard surface. With long experience, one can judge whether grain was suitable for storage, that is, whether it was wet, damp, dry or over dry. It is generally known that wet and damp grain are 'softer' compared with dry or very dry grain. Also, wet or damp grain give dull sound, smells 'off' and prevents penetration by the hand (Hall, 1970). However, one cannot rely on these methods due to inconsistency and no two people can reproduce the same results.

According to Appert (1987), produce drying by the small 
farmers is done in a rudimentary fashion, its effects are incomplete and the operation is not easy to regulate. Even with such shortcomings, the efforts made should be acknowledged and improved where possible. The National Academy of Science (1978) summarized the situation in:

"The post-harvest system of storing and handling of crops is suited to the type and level of production in which it has evolved. These levels are constrained by resources available to the farmer, especially the labour. Traditional practices are therefore, unlikely to be abandoned unless the replacements can be shown to be effective and easy to work with" (Anon 1978). This is what needs to be understood before anyone can introduce new technologies to farmers.

\subsection{Background}

Initially, the Catholic Relief Services (CRS) introduced metal silos for grain storage to small scale farmers in Suba and Homa Bay districts with the aim of making food availability more secure as well as raise the family income in the otherwise food deficit areas. Farmers were trained on how to use the silos while local artisans learned to fabricate in order to create a sustainable demand and supply line. The project was later extended to districts in Central and the Eastern Provinces, but grain moisture management was a threat. The project introduced the 'salt and bottle' method to enable farmer determine if maize was dry enough for metal silo storage. The method works on the principle that dry salt does not stick on a dry surface, meaning that salt crystals would only stick on to improperly dried grain. While this appeared logical, the method remains subjective as it was not easy to ascertain the moisture at which salt would not stick to the grain surface. The postharvest research at the National Agricultural Research Laboratories (NARL) undertook to verify whether the grain moisture that did not allow salt to adhere to grain was also safe for storage especially in metal silos under the CRS project.

\subsection{Objectives}

a) To establish the moisture level at which salt stops sticking on to the grain surface;

b) To establish the time taken for maize at different levels of moisture content to dry to safe level for storage.

\section{Methodology}

Grain samples were collected from Murang'a, Machakos and Kitui the three catholic dioceses under the CRS project. Farmers to be visited were selected by the CRS field staff in each respective diocese. Five farmers from Kirinyaga and four from Murang'a made the sampling units from the Murang'a diocese, while both Machakos and Kitui dioceses had ten farmers each. The sampling method was influenced by the grain quantity available. For small quantities, the grain spear was used to extract samples paying particular attention to representation (Harris and Lindblad 1978). Full bags and metal silos were sampled using the double tube 5 compartment grain probe along the 8-compass directions. Several probes were required to make $1 \mathrm{~kg}$ samples for analysis. In the laboratory, grain moisture in each sample was established using a Dickey john moisture meter as between $11 \%$ and $17.2 \%$. A 5 moisture range from $12 \%$ to $20 \%$ was therefore adopted for the trial. Samples from one diocese were bulked and thoroughly mixed before weighing $1 \mathrm{~kg}$ into $1 \frac{1}{2}$ litre glass jars. Five such jars were required for each diocese and another five for the control. To have grain at 14 $20 \%$ moisture content (MC), calculated amounts of distilled water were added (Harris and Lindblad, 1978) and the jars shaken daily for three weeks before storage in deep freezer. Grain at $12 \% \mathrm{MC}$ was stored under ambient room conditions.

A kilogram of common table salt was placed in thin layer in the oven at $100^{\circ} \mathrm{C}$ for one hour to ensure it was dry enough not to stick on glass sides. After three weeks of moisture equilibration, $200 \mathrm{~g}$ of grain from each moisture level was weighed into $1 / 2$ litre glass jars replicated twice. To each of the 30 jars, $20 \mathrm{~g}$ of dried salt was added and shaken for 30 seconds. Ten other jars were not salted and served as the control. All jars were allowed to stand for 30 minutes before attempting to remove the salt. The content of each jar was then placed in a $4.75 \mathrm{~mm}$ aperture size sieve with a bottom pan and lid and gently shaken for 10 seconds. The salt collected was weighed and the sieve cleaned with a brush and cotton wool before the next sieving. The process was repeated five days later in an attempt to account for all the salt. To determine the rate of drying for the different moisture levels, only the maize used as the control was used. On sunny days, grain was spread in plastic trays and moisture determined at hourly intervals. Under shade drying, to simulate overcast skies, was done on laboratory benches and grain moisture determined at the end of each day.

\section{Results}

\subsection{Amount of Salt Recovered after 30 Minutes Post Application}

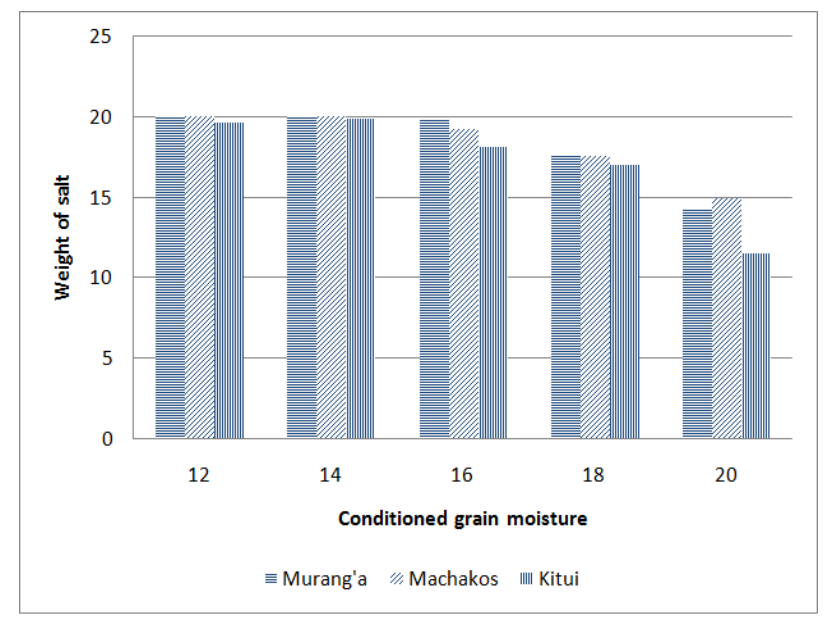

Fig. 1. Amount of salt recovered from maize samples at different moisture levels from three Catholic Dioceses 30 minutes after treatment 
As Fig.1 shows, the amount of salt sticking to the grain was dependent on grain moisture level. At $12 \%$ all the $20 \mathrm{~g}$ were recovered from maize samples from Murang'a and Machakos while $0.2 \mathrm{~g}$ could not be accounted for in Kitui samples. The same trend was observed on maize at $14 \% \mathrm{MC}$ when $0.1 \mathrm{~g}$ of salt could not be accounted on samples from the same diocese. At higher GMC (What is GMC?) \%, the amount of salt sticking on to the grain increased with increase in moisture level. Thus at $16 \%$ GMC, Murang'a samples retained $0.2 \mathrm{~g}$ compared with $0.8 \mathrm{~g}$ and $1.9 \mathrm{~g}$ for Machakos and Kitui samples respectively. At the next level, $2.4 \mathrm{~g}, 2.5 \mathrm{~g}$ and $3.05 \mathrm{~g}$ of salt remained stuck on grain while between $5.75 \mathrm{~g}$ and $8.55 \mathrm{~g}$ stuck on maize at $20 \%$ GMC. The average quantity that stuck on grain for the five moisture levels was $0.2,0.1,1.04,3.0$ and $6.47 \mathrm{~g}$. From these findings, it was clear that farmers from the three dioceses would classify maize at $14 \%$ and even some at $16 \%$ GMC as dry for safe storage due to the minute quantities that stuck on grain (Fig 1). Only farmers from Machakos and Kitui dioceses would be concerned based on $0.85 \mathrm{~g}$ and $1.95 \mathrm{~g}$ that stuck.

\subsection{Time Taken for Maize at Different Moisture Levels to Dry for Safe Storage}

Fig. 2 shows grain moisture dropped steadily from day 1 to day 4 when equilibrium was attained. From $16 \%$ to $20 \%$ GMC, the grain lost $3-6 \%$ while at $14 \%$ the loss was only $2 \%$ in the first three days. Grain at $12 \%$ had minimal changes. By the fifth day, all GMC levels equilibrated at $13 \%$ and remained so at the $7^{\text {th }}$ day. Considering that farmers would regard the $0.1 \mathrm{~g}-0.2 \mathrm{~g}$ the amount of salt that remained stuck on grain at $14 \%$ and $16 \%$ GMC as negligible, it was necessary to establish additional time required to dry to safe for storage level. The number of days it took for such moisture to drop to the level safe for storage was established as between 2 and 3. However, this would be safe only for conventional bag storage and for metal silos, further drying was necessary.

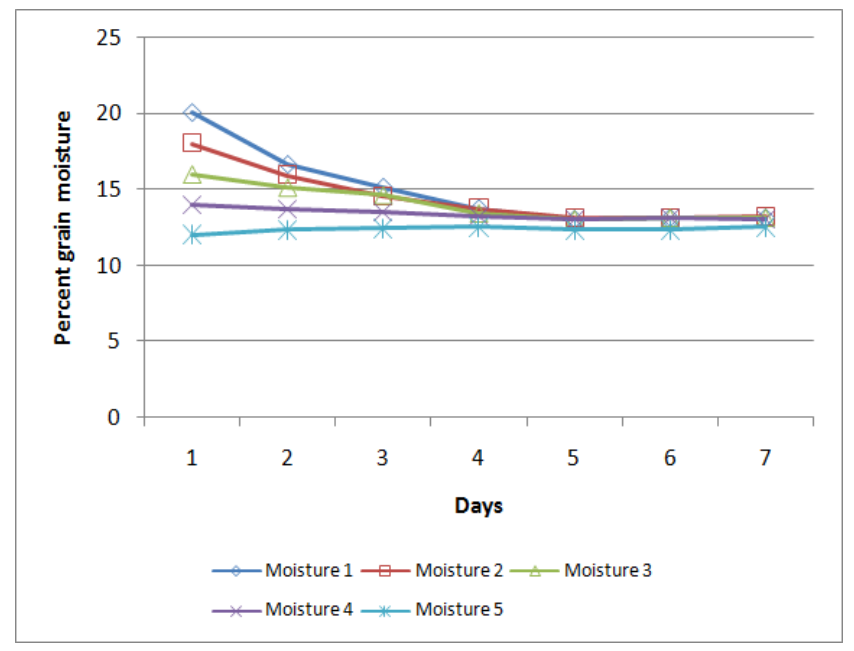

Fig. 2. Time taken for maize to dry to safe moisture for storage under ambient room conditions

Drying in the sun was carried out with four samples after the maize at $20 \%$ developed moulds. Fig. 3 shows that rapid grain drying occurred within the first three hours when between $1 \%$ and $3.6 \%$ GMC was lost across the four moisture levels. In the next three hours, further drying continued with $0.4-2.4 \%$ water loss. Within the first three hours, grain at $12 \%$ - 16\% GMC had reached $13.4 \%$ and below, meaning it could safely be stored in conventional bag storage. Grain at $18 \%$ required another 3 hours of drying at which time all samples had between $10.6 \%$ and $12 \%$ moisture. On the $4^{\text {th }}$ day of sun drying, all the grain moisture had equilibrated between $10.5 \%$ and $10.9 \%$. Although grain moisture was between $10 \%$ and $12 \%$ after 10 cumulative hours of drying, it was only after 15 cumulative hours that GMC reduction was between 0.0 and $0.2 \%$. Such minimal fluctuation indicated grain could safely be stored in metal silos without any deterioration risk.

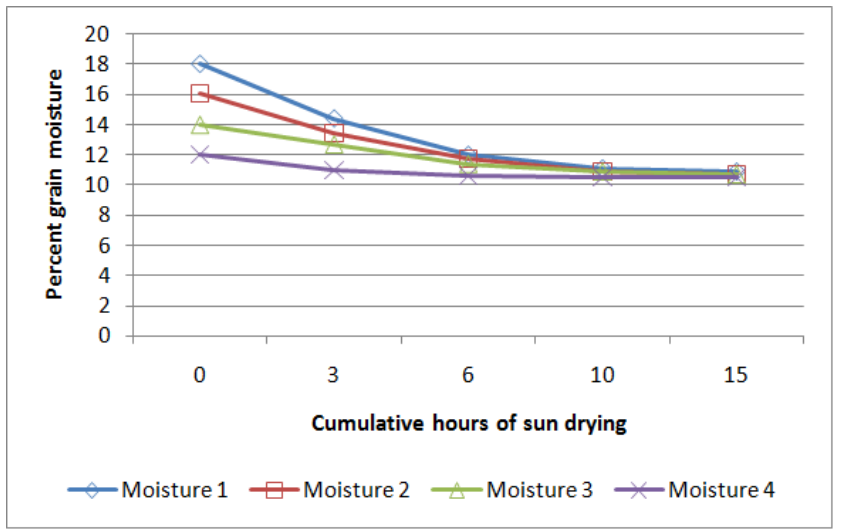

Fig. 3. Time taken to dry maize in the sun to safe moisture for storage)

\section{Discussion}

The moisture level at which salt failed to stick on to the grain surface was not the same for all maize samples. At $12 \%$ and $14 \%$, up to $0.4 \mathrm{~g}$ were found to stick on grain from Kitui and on average, the amount sticking across all the GMC was $0.1,0.2,1.04,3.0$ and 6.47 . No doubt farmers would regard the first two amounts as negligible and would therefore be ready to put the maize into their metal silos. While the safe moisture for storage of maize in bags (the conventional storage practice) is $13.5 \%$ (Hall, 1970; Anon, 1977; Walker, 1994), the same would not be true for the commonly used polypropylene bags whose weave does not allow free air circulation during prolonged storage. Woven sisal bags allow grain moisture exchange with the surrounding air and so ensure quality was maintained.

In metal silos, the risk of moisture migration resulting in condensation at cooler upper layers has been the main challenge (Hall, 1970). This is because moisture exchange is not as efficient as it is in bags. If maize at $14 \%-16 \%$ moisture, the level at which farmers would not notice the salt sticking on grain was stored, as some samples indicated; deterioration would occur due to the above reason. Grain can take in or give out moisture to the surrounding environment and the phenomenon is catalyzed by changes in temperature 
and relative humidity (Hall, 1970; Walker, 1994). For this reason, extra grain drying (to $10 \%-11 \%$ ) as achieved by use of the sun was advantageous. Hall (1970) further recommend that metal silos should be light in colour and provided with adequate shade to keep temperatures constant.

Natural grain drying relies on the sun and depending on the season, there are times when the sun does not shine at all. Under-shade drying showed that it was possible for grain moisture to drop from initially high of above $14 \%$ to $13.5 \%$, (safe moisture for storage) within 3 to 5 days, when maize was spread in thin layer. It is interesting to note that grain with low moisture took longer to dry, for example, at $14 \%$ it took 7-days of drying in the shade for the moisture to drop to $13 \%$, one level above the anticipated moisture for safe metal silo storage. Drying maize in the sun took much shorter time, only 6 hours for moisture to drop from $18 \%$ to $12 \%$. However, it was only after 15 hours that the moisture stabilized around $11 \%$, the level at which farmers can safely store maize in metal silos for prolonged storage.

The small study only re-affirms that all those involved in the handling of durable produce do understand the importance of drying. Though with shortcomings, farmer methods may be rudimentary but serve their purpose. When new technologies are introduced, there is the challenge on how to bring them at par with modern methods. Validation with intention to fine tune technology is one way to ensure farmers make good use of their indigenous technical knowledge (ITK) (Ngatia, 2012). It is from this that the author has recommended extra grain drying for metal silo users.

\section{Conclusion}

The salt and bottle method proved to be a good guide on when maize could be stored. Through validation, it is now possible to relate the point at which salt does not stick to grain surface to a given moisture level. To avoid deterioration that can arise from blanket adherent to that point, farmers are advised to further dry grain for at least two days to ensure grain moisture was within the safe level for the adopted storage method.

\section{Acknowledgements}

The reported work was the result of collaboration between the postharvest research at KARI Kabete and the CRS, metal silo project. The author duly appreciates the support from the two institutions.

\section{References}

[1] Anon 1977: The Kenya Standard, Specification for dry shelled maize (KS 01 - 42: 1977), UDC 633.15

[2] Anon 1978: The Board of Science and Technology for International Development, Commission of International Relations, National Research Council, National Academy of Science, 1978. Congress Catalogue Number 78-70607.

[3] Appert, J. 1987: The storage of food grains and seeds. (The Tropical Agriculturist). ISBN 0-333-44827-8.

[4] Hall, D. W., (FAO Consultant) 1970: Handling and storage of food grains in Tropical and sub-tropical areas. FAO-UN, Rome.

[5] Harris, K. L. and Lindblad, C. J.1978: Post-harvest Grain Loss Assessment Methods. A Manual for the evaluation of postharvest losses. American Association of Cereal Chemists. ISBN 0-913250-14-7

[6] Ngatia, 2012: Research - Farmer Interface: a place for ITK in Kenya. MSc: Agricultural Education Dissertation, 1993, Reading University. Publisher: Lap Lambert Academic Publishing GmbH \&Co.KG ISBN: 978-3-8484-0361-5.

[7] Walker, J. D. (Ed), 1994: World Food Programme/Natural Resource Institute: food storage manual. ISBN 0859543137. 